\title{
LSD: a new treatment emerging from the past
}

$\mathrm{P}$ sychedelics fell from medical grace nearly half a century ago, but recent activity suggests that some researchers have "high hopes" for their return. ${ }^{1,2}$ Over 60 years ago, Albert Hofmann at Sandoz Pharmaceutical Laboratories in Switzerland first synthesized lysergic acid diethylamide (LSD) and personally experienced its effects (later described as a voyage into madness or a chemically induced psychosis) in 1943. Hofmann's drug opened up a new era of hallucinogenic research. Over the next 15 years, more than a thousand articles on the use of LSD appeared in medical and scientific publications. In 1957, that work gave rise to the term "psychedelic" to describe a mind-manifesting response, described by some as an experience that brought to light matters that had previously been part of the unconscious.

During the 1950s and into the early 1960s, LSD was used rather successfully to treat alcoholism, arguably by compressing years of psychotherapy into a single, intensive, self-reflective session that helped patients with alcohol dependence achieve a new self-image and the willpower to move beyond their disease. Others explored LSD as an adjuvant to psychotherapy for addressing trauma; still others used it to model psychosis and to generate interest in studying schizophrenia as a chemical reaction in the brain. However promising these studies were, they also invited critics who argued that LSD did not perform well in randomized controlled trials, that the drug was too enticing as a substance for abuse or that it was an altogether dangerous substance given its capacity for conjuring terrifying hallucinations or producing psychosis.

By the mid-1960s, however, scientific criticism was somewhat moot. Research into LSD came to a decided halt, largely because it had become synonymous with countercultural activities,

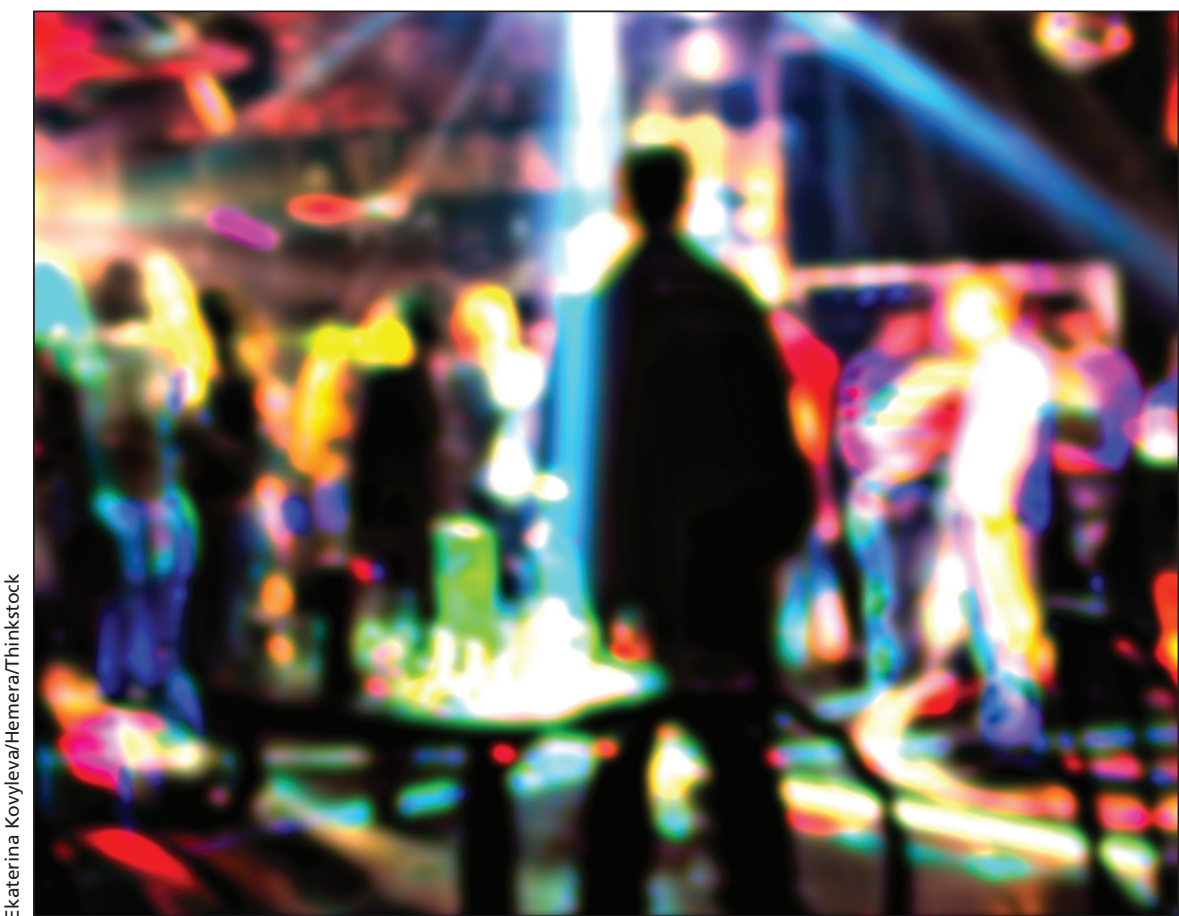

hedonism and drug abuse. By the end of that colourful decade, LSD was considered in many jurisdictions as a prohibited substance, and its clinical applications were moved to the margins of acceptable medicine. ${ }^{3}$

Over the past few years, that situation has started to change. A new generation of researchers has taken up the torch with a goal of resurrecting the psychedelic science of the 1950s, particularly along the paths of addiction research and palliative care. Will this new group of enthusiasts be more nimble, or have cultural circumstances changed sufficiently to embrace psychedelics anew?

Historians are not good at predicting the future, so I won't; we are trained, however, to examine social context and change over time, which is useful for identifying trends and assigning causality, with hindsight on our side. The incarnation of psychedelic research in the 21 st century resurrects some of the old hypotheses and explores some of the same applications that clinicians experimented with 50 years ago. On the surface, the psychedelic renaissance might be dismissed for retreading familiar ground. A deeper look at the cultural context suggests that psychedelic drug research in the 21st century may have changed enough to warrant a retrial.

Neuroscience was in its infancy in the 1950s when LSD researchers first postulated that receptors were involved in regulating psychotic symptoms, among other things. Reactions to LSD seemed to suggest that areas of the brain could be turned on and off, or that different levels of consciousness could be activated through the use of chemicals. Yet the prohibition of LSD and its psychedelic cousins was not simply the result of unsophisticated science; drug regulators played a role in squeezing them out of legitimate existence based on assumptions about their perceived dangers, adverse effects and appetite for abuse. 
In Canada, the story of LSD's regulation is particularly revealing. The issue first arose in 1962 amid the thalidomide scandal. As regulators discussed the appropriate schedule for thalidomide, they paused to consider whether LSD should be placed under similar restrictions. The medical community at that moment banded together to defend the prerogative of clinicians to set the criteria for determining the efficacy of a drug. A few years later, under pressure from the Senate led by Senator Hartland Molson of the Molson Brewery family, physicians yielded to the recommendations of policymakers. ${ }^{4}$ Suffice to say, the leading therapeutic application was using LSD to treat alcoholism, and Senator Molson pushed the law forward, while the brewing industry enjoyed regulations that helped bring beer to market.

The bureaucracy of drug regulation has grown exponentially over the past half century and has recently come under criticism for making political rather than evidence-based decisions. In 2007, British pharmacologist David Nutt published a harm-ranking scale in The Lancet, where he argued that psychedelic drugs were much less harmful than the regulated substances of nicotine and alcohol. ${ }^{5} \mathrm{He}$ was later fired from his position on the Advisory Council on the Misuse of Drugs, which catapulted him into the debates over renewing medical research on psychedelics. He subsequently pointed to the gulf that has grown between clinical drug trials and government regulations, lamenting the "daunting bureaucratic labyrinth that can dissuade even the most committed investigator."

Liberal regulation may contribute to hyperbolic scientific claims and overzealous research agendas, but tight regulatory controls may quash potential therapies or the development of basic scientific information. Regulation has come to represent a degree of safety and reduced liability that facilitates getting a drug to market, rather than setting the research parameters for a novel substance or a novel application. ${ }^{7-9}$ Does this imply that scientists and drug regulators will find themselves at cross-purposes? A 21 st century resurgence of psychedelic research suggests this may be the case.

Evidence is mounting that a new era of psychedelic medicine may be around the corner. Laboratories in the United States and Europe have already been conducting trials for several years. The historical context may have changed to permit these experiments, but who will champion this next phase of psychedelic science? In 1963, Aldous Huxley received LSD on his death bed and suggested that its effects bathed him in a vision of warmth and spiritual belonging, such that he could face death without fear. Palliative care has been an area identified for the potential use of psychedelics for precisely this reason; not as a treatment, but as a psychological therapy that helps people face death. Will the growing need for palliation change the context sufficiently to warrant a second look at
LSD clinically? As baby boomers age, placing greater demands on end-of-life care than we have faced in the past, will they again tip the demographic scales and create sufficient patient demand for LSD?

\section{Erika Dyck PhD}

Department of History, University of Saskatchewan, Saskatoon, Sask.

\section{References}

1. Langlitz N. Neuropsychedelia: the revival of hallucinogen research since the decade of the brain. Berkley. Oakland (CA): University of California Press; 2013.

2. Kupferschmidt K. High hopes. Science 2014;345: 18-23.

3. Oram M. Efficacy and enlightenment: LSD psychotherapy and the drug amendments of 1962 . J Hist Med Allied Sci 2014;69:221-50.

4. Dyck E. Just say know? Criminalizing LSD and the politics of psychedelic expertise, 1961-1968. In: Montigny E, editor. The real dope. Toronto: University of Toronto Press; 2011:169-96.

5. Nutt D1, King LA, Saulsbury W, et al. Development of a rational scale to assess the harm of drugs of potential misuse. Lancet 2007;369:1047-53.

6. Editors. End the ban on psychoactive drug research. Sci Am 2014;310(2):33. Available: www.scientific american.com/article/end-the-ban-on-psychoactive -drug-research/ (accessed 2015 Apr. 2).

7. Marks H. The progress of experiment: science and therapeutic reform in the United States, 19001990. Cambridge (MA): Cambridge University Press; 1997.

8. Healy D. Let them eat Prozac: the unhealthy relationship between the pharmaceutical industry and depression. New York: New York University Press; 2004.

9. DeGrandpre R. The cult of pharmacology: how America became the world's most troubled drug culture. Durham (NC): Duke University Press; 2006.

Funding: This project was funded by a grant from the Social Sciences and Humanities Research Council and a salary award through the Canada Research Chair in the History of Medicine (Tier 2). The funding had no direct impact on the author's research or conclusions.

CMAJ 2015. DOI:10.1503/cmaj.141358

\section{What happened to you?}

I reek of salt water: the breath of the Indian Ocean lingers on my tanned skin and sweat trickles down my back, my legs, my nose. A bony elbow juts into my ribs and a stranger's hand rests familiarly on my shoulder while another calloused hand overlaps my own on a sticky, metallic surface: an ordinary train pole suddenly transformed into a quasi-artistic exhibit of palms and digits, a tenuous resting place for desperate hands and reaching fingers, many settling atop one another. To think that a sudden jolt would cause me to lose my balance is absurd; I cannot move. I clutch the pole, an anchor in a sea of bodies, salt water, sweat.

Miraculously, inexplicably, each stop brings more evening commuters. They can't possibly get on. But they do.
Every inhalation is laborious, the breath knocked out of my lungs as people vie for precious space, pushing against my chest, stomping on my feet. I close my eyes, but this only amplifies the impression of making physical contact with a dozen pulsating bodies at once.

Deep breaths. I count each inhalation: One. Two. Three. I count the barely illuminated stops as they go by: One. 